\title{
Hole-Buffer Material Derived from Pyrene, Schiff Base and Tris to Enhance Emission Efficiency of Polymer Light-Emitting Diodes
}

\author{
Jyun-Huei Liou, Ping-Feng Hsu, Yun Chen* \\ Department of Chemical Engineering, National Cheng Kung University, Taiwan \\ Email: *yunchen@mail.ncku.edu.tw
}

How to cite this paper: Liou, J.-H., Hsu, P.-F. and Chen, Y. (2018) Hole-Buffer Material Derived from Pyrene, Schiff Base and Tris to Enhance Emission Efficiency of Polymer Light-Emitting Diodes. Journal of Materials Science and Chemical Engineering, 6, 31-46.

https://doi.org/10.4236/msce.2018.63003

Received: January 31, 2018

Accepted: March 17, 2018

Published: March 20, 2018

Copyright $\odot 2018$ by authors and Scientific Research Publishing Inc. This work is licensed under the Creative Commons Attribution International License (CC BY 4.0).

http://creativecommons.org/licenses/by/4.0/

(c) (i) Open Access

\begin{abstract}
Inserting a hole-buffer layer is an effective way to enhance emission efficiency of electroluminescence devices. We have successfully synthesized a new hole-buffer material PSB composed of pyrene, Schiff base and trihydroxy tert-butyl groups by the Suzuki-coupling reaction. The HOMO and LUMO levels were $-6.33 \mathrm{eV}$ and $-2.55 \mathrm{eV}$, respectively, as estimated from cyclic voltammograms. In addition, homogeneous films (rms roughness $\sim 2 \mathrm{~nm}$ ) were readily obtained by spin-coating process. Multilayer polymer light-emitting diodes, ITO/PEDOT:PSS/PSB/SY/LiF/Al, have been fabricated using PSB as hole-buffer layer (HBL). Inserting PSB as HBL significantly enhances the performance (maximum luminance: $26,439 \mathrm{~cd} / \mathrm{m}^{2}$, maximum current efficiency: $7.03 \mathrm{~cd} / \mathrm{A})$, compared with the one without PSB $\left(9802 \mathrm{~cd} / \mathrm{m}^{2}, 2.43\right.$ $\mathrm{cd} / \mathrm{A})$. It is also superior to the device with conventional $\mathrm{BCP}$ as hole-blocking layer (ITO/PEDOT:PSS/SY/BCP/LiF/Al: 15,496 cd/m², $5.56 \mathrm{~cd} / \mathrm{A}$ ). Current results strongly indicate that the PSB is a potential hole-buffer material for electroluminescent devices.
\end{abstract}

\section{Keywords}

Hole-Buffer, Polymer Light-Emitting Diodes, Pyrene, Schiff Base, Spin-Coating

\section{Introduction}

Organic light-emitting diodes (OLEDs) and polymer light-emitting diodes (PLEDs) have attracted considerable attention from both academic and industrial points of view due to promising applications in flat panel displays and solid-state lightings [1] [2] [3]. Device efficiency of OLEDs and PLEDs depend 
mainly on the recombination ratio of holes and electrons injected from anode and cathode, respectively. Balance in holes and electrons (high carriers' recombination ratio) is crucial in enhancing device emission efficiency [4] [5] [6]. However, hole mobility in most organic materials is higher than electron mobility [6]; moreover, the injection rate of holes for most OLED/PLED devices is greater than that of electrons. This leads to imbalanced carriers and reduced device efficiency. Carriers balance can be improved by multilayer device structure, i.e., inserting electron injection and transport layers between emission layer and the cathode [7] [8]. In this way, the injection and transport of electrons are raised to a level comparable to those of holes, resulting in more balanced carriers. Another effective strategy is to inserta hole-blocking layer between emissive layer and electron injection layer, such as bathocuproine (BCP), 2,2',2"-(1,3,5-benzinetriyl)-tris(1-phenyl-1-H-benzimidazole)(TPBi) and 1,3,5-tri (m-pyridin-3-ylphenyl) benzene (TmPyPB). The hole-blocking layer effectively confines the holes and excitons within the emissive layer due to its low HOMO level [9] [10] [11] [12]. Although this hole-blocking effect can accumulate holes within emissive layer to increase recombination ratio, the recombination region is usually a narrow zone close to the hole-blocking layer. The formation of excitons too near the interface usually leads to diminished color purity and emission efficiency [13].

Recently, hole-buffering materials have been developed to increase the recombination ratio and emission efficiency. The hole-buffering materials effectively reduce the mobility of holes, instead of increasing injection/transport of electrons, to raise the recombination ratio of carriers. For instance, copper (II) phthalocyanine (CuPC), and 4,4',4"-tris (N-carbazolyl)-triphenylamine (TATC) were deposited as hole-buffering layer which effectively reduced hole mobility [14] [15]. We have designed a polymer $3 \mathbf{P}_{5} \mathbf{O}$ composed of alternating $p$-terphenyl and tetraethylene glycolether segments and successfully employed as hole-bufferlayer to improve carriers balance [16]. The hole buffer layer was inserted between hole injection and emissive layers, it reduces the mobility of holes and thus recombine with electrons in the whole emissive layer, leading to enhanced device performance [16] [17]. In 1999, Forsythe found that transport of holes from ITO anode to NPB hole-transporting layer was injection-limited and device performance depended on hole current [18]. They inserted different thickness of CuPC $(0-30 \mathrm{~nm})$ to reduce hole-injection into the emissive layer and effectively enhanced device performance. However, the CuPC layer should be formed by vacuum thermal deposition, whose disadvantages are high cost of fabrication processes and difficulty in fabricating large-area devices than solution process [19] [20]. In solution process, polymers are usually used because of their excellent film-forming property. Although this advantage makes polymers very appropriate for PLEDs, some inherent difficulties are still existed for polymers applied in PLEDs, such as purification, control of batch-to-batch variations and wide distribution of molecular weight. On the contrary, the advantages of small 
molecules applicable in solution process are exact molecular structure and high purity. However, some problems may emerge when applied to device fabrication using solution processes, such as limited film-forming property and poor morphology in film state [20].

In this study, we have designed and successfully synthesized a new small molecular hole-buffering material PSB by the Suzuki-coupling reaction. The core of PSB is a pyrene symmetrically attached with two phenol groups, from which imine (Schiff base) and trihydroxy tert-butyl groups are linked. The pyrene core is introduced to raise hole transport ability [21]; however it aggregates readily due to its flat structure [22]. The aggregation may cause aggregation or crystallization during device operation, which becomes as defect in PLEDs to reduce device efficiency and life times. To solve this problem, bulky trihydroxy tert-butyl groups are introduced to prevent aggregation by steric hindrance. Moreover, PSB is inserted with imine linkage (Schiff base) between phenol and trihydroxy tert-butyl groups. The electron-withdrawing propensity of imine moiety is expected to slow down hole-transporting rate. In addition, homogeneous film of PSB was readily obtained by solution process. Multilayer OLED devices were fabricated by using PSB as hole-buffering layer [ITO/PEDOT:PSS/PSB/SY/LiF/Al]. The optimal performance of PSB-based device (maximum luminance: 26,439 $\mathrm{cd} / \mathrm{m}^{2}$, maximum current efficiency: $7.03 \mathrm{~cd} / \mathrm{A}$ ) is much better than the one without PSB [ITO/PEDOT:PSS/SY/LiF/Al] $\left(9,802 \mathrm{~cd} / \mathrm{m}^{2}, 2.43 \mathrm{~cd} / \mathrm{A}\right)$. Furthermore, the performance also surpasses the device with conventional $\mathrm{BCP}$ as hole-blocking layer [ITO/PEDOT:PSS/SY/BCP/LiF/Al] $\left(15,496 \mathrm{~cd} / \mathrm{m}^{2}, 5.56 \mathrm{~cd} / \mathrm{A}\right)$. Apparently, the hole-buffering property of PSB is effective in enhancing emission efficiency of electroluminescent devices.

\section{Materials and Methods}

\subsection{General Procedures}

Thermal degradation and transition behaviors of the PSB were investigated using thermogravimetric analysis (TGA) and differential scanning calorimetry (DSC), respectively. The TGA was conducted under a nitrogen atmosphere, heated from ambient temperature to $580^{\circ} \mathrm{C}$ at a rate of $10^{\circ} \mathrm{C} / \mathrm{min}$ using a PerkinElmer TGA-7 thermal analyzer. The thermal decomposition temperature $\left(\mathrm{T}_{\mathrm{d}}\right)$ was determined at $5 \%$ weight loss of the sample. The thermal transitional properties were measured from $-100^{\circ} \mathrm{C}$ to $260^{\circ} \mathrm{C}$ under a nitrogen atmosphere, using a DSC 2010 from TA Instruments. The glass transition temperature $\left(\mathrm{T}_{\mathrm{g}}\right)$ was determined from the second heating scan. Cyclic voltammograms (CVs) were measured with a voltammetric apparatus (model CV-50W from BAS) equipped with a three-electrode cell. The cell was made up of a glassy carbon as the working electrode, an $\mathrm{Ag} / \mathrm{AgNO}_{3}$ electrode as the reference electrode, and a platinum wire as the auxiliary electrode. The electrodes were immersed in acetonitrile containing $0.1 \mathrm{M}(n-\mathrm{Bu})_{4} \mathrm{NClO}_{4}$ as the electrolyte. The energy levels were calculated using the ferrocene (FOC) value of $-4.8 \mathrm{eV}$ with respect to vacuum level, 
which is defined as zero. Absorption and photoluminescence (PL) spectra were measured with a Jasco V-550 spectrophotometer and a Hitachi F-4500 fluorescence spectrophotometer, respectively. The surface morphologies of deposited films were measured with an atomic force microscope (AFM), a Dimension Icon from Bruker. The film thickness was measured with a surface profilometer (Surfcorder ET4000 M).

\subsection{Synthesis of PSB [23]}

The synthetic routes of the pyrene derivative PSB are shown in Scheme 1. To a sodium carbonate solution $(0.6 \mathrm{M}, 2.8 \mathrm{~mL})$ in $50-\mathrm{mL}$ glass reactor was added with 2, 7-bis (4,4,5,5-tetramethyl-1,3,2-dioxaborolan-2-yl) pyrene (1: $0.2 \mathrm{~g}, 0.44$ mmol), 5-bromo-2-hydroxybenzaldehyde (2: $0.264 \mathrm{~g}, 1.32 \mathrm{mmol})$, and tri-tert-butylphosphonium tetrafluoroborate $(0.032 \mathrm{~g}, 0.11 \mathrm{mmol})$. The solution of tris (dibenzylideneacetone) dipalladium $(0)\left(\mathrm{Pd}_{2}(\mathrm{dba})_{3}: 57 \mathrm{mg}, 0.06 \mathrm{mmol}\right)$ in THF $(18 \mathrm{~mL})$ was added into the reactor by a syringe. The mixture was stirred at $65^{\circ} \mathrm{C}$ for two days to afford 5,5'-(pyrene-2, 7-diyl)bis(2-hydroxybenzaldehyde) (3). A mixture of 3 ( $0.15 \mathrm{~g}, 0.39 \mathrm{mmol}$ ), 2-amino-2-(hydroxymethyl) propane-1, 3-diol (4: $0.41 \mathrm{~g}, 3.9 \mathrm{mmol})$ and methanol $(150 \mathrm{~mL})$ was stirred at $65^{\circ} \mathrm{C}$ for two days. The methanol was removed by arotary evaporator to obtain a crude product, which was further washed thoroughly with water and acetone several times to obtain PySb (yield: 0.20 g, 90.8\%). The structure of $\mathbf{3}$ and PSB hve been successfully confirmed by ${ }^{1} \mathrm{H}$ NMR and elemental [23].

\subsection{Devices Fabrication and Measurements}

ITO glass substrates were cleansed successively, in an ultrasonic cleaner, with neutral detergent, deionized water, acetone, and isopropyl alcohol at $45^{\circ} \mathrm{C}$, each for $20 \mathrm{~min}$. Then the substrates were further treated in a UV-ozone chamber for 20 min to remove trace organic contaminants. A solution of PEDOT:PSS was spin-coated onto the ITO surface to deposit the hole-injection layer, followed with baking at $140^{\circ} \mathrm{C}$ for $20 \mathrm{~min}$. Next, a PSB solution in N, N-dimethylformamide (DMF) was spin-coated on top of the PEDOT:PSS layer to form as hole-buffering
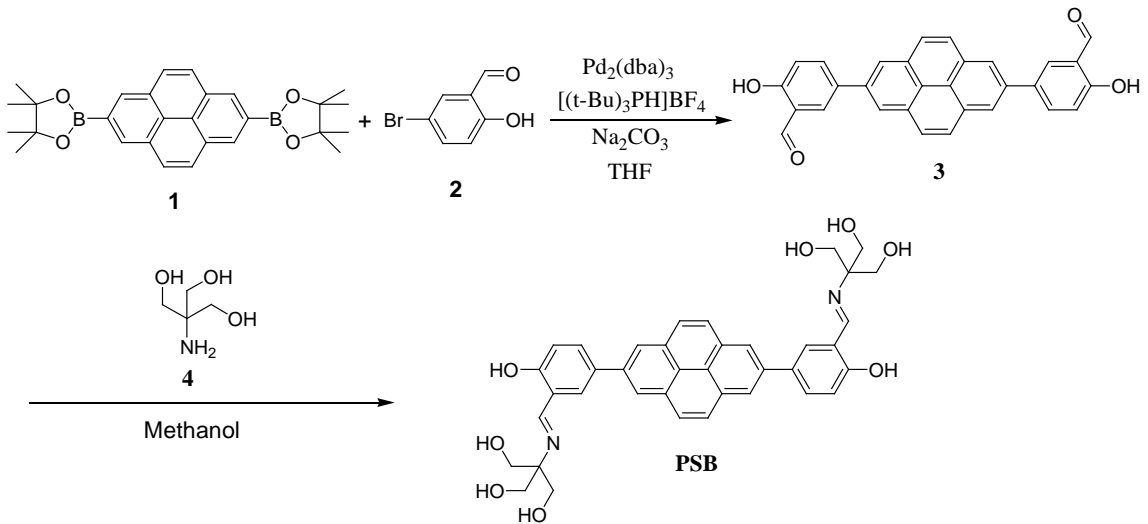

Scheme 1. Synthetic procedures of pyrene-Schiff base derivative PSB. 
layer, followed by annealing at $70^{\circ} \mathrm{C}$ for $20 \mathrm{~min}$. The emission layer was spin-coated from a toluene solution of Super Yellow (SY, Merck), followed with annealing at $70^{\circ} \mathrm{C}$ for $20 \mathrm{~min}$. Finally, the substrate was transferred into a vacuum chamber to deposit $\operatorname{LiF}(1 \mathrm{~nm})$ as an electron injection layer and then aluminum $(90 \mathrm{~nm})$ as the cathode, at a pressure less than $2 \times 10^{-6}$ Torr. Finally, current density-voltage-brightness $(\mathrm{J}-\mathrm{V}-\mathrm{L})$ characteristics of the devices were recorded using a combination of a Keithley power source (model 2400) and an Ocean Optics usb2000 fluorescence spectrophotometer.

\section{Results and Discussion}

\subsection{Thermal, Photo-Physical and Electrochemical Properties}

Thermal decomposition behavior of PSB was investigated by thermogravimetric analysis under nitrogen atmosphere, between room temperature and $580^{\circ} \mathrm{C}$. As shown in Figure 1, the thermal degradation of PSB is a two-stage process, including a quick weight loss at about $300^{\circ} \mathrm{C}$ and a slow degradation between $300^{\circ} \mathrm{C}$ and $580^{\circ} \mathrm{C}$. The first quick weight loss is attributable to thermal decomposition of terminal imine and trihydroxy tert-butyl groups, whereas the latter slow degradation should be caused by the decomposition of aromatic chromophores. The thermal decomposition temperature $\left(T_{d}\right)$ at $5 \%$ weight loss was about $300^{\circ} \mathrm{C}$, indicating it is thermally stable to be applied in PLEDs. Thermal transitional properties of PSB were studied by differential scanning calorimetric (DSC) measurements between $-100^{\circ} \mathrm{C}$ and $260^{\circ} \mathrm{C}$. A glass transition temperature $\left(T_{g}\right)$ was observed at about $20^{\circ} \mathrm{C}$ (inset), without detectable crystallization and melting transitions. Soft and bulky trihydroxy tert-butylterminals give rise to low glass transition temperature. Moreover, these bulky terminals are effective in preventing regular molecular packing into crystallites, resulting in amorphous solid state.

The absorption and photoluminescence spectra of PSB in DMF solution $\left(10^{-5}\right.$ $\mathrm{M})$ and as thin film spin-coated from DMF solution $(10 \mathrm{mg} / \mathrm{mL})$ are illustrated in Figure 2, with characteristic data summarized in Table 1. In DMF solution, PSB revealed three absorption peaks at 267, 307 and $342 \mathrm{~nm}$, attributable to the hydroxyl groups $n-\pi^{\star}$ transition, pyrene and aryl groups $\pi-\pi^{*}$ transition [24], and imine groups $\pi-\pi^{\star}$ transition [25], respectively. In film state, two absorptions at $294 \mathrm{~nm}$ and $430 \mathrm{~nm}$ were observed; the former is ascribed to blue shiftedabsorption of pyrene and aryl groups, while the latter is caused by the aggregation of PSB [26]. In DMF solution, PSB shows a weak emission peak at $515 \mathrm{~nm}$ (normalized), attributed to pyrene and aryl groups. However, no emission was detectable in film state, due probably to complete fluorescence quenching caused by the two terminal Schiff base (imine) groups. The fluorescence of excited pyrene groups is prohibited by photo-induced electron transfer (PET) from imine moieties [27]. Non-fluorescence of PSB is a great merit for electroluminescent devices, because its will not degrade color purity of the emissive layer when used as hole-buffer layer. 


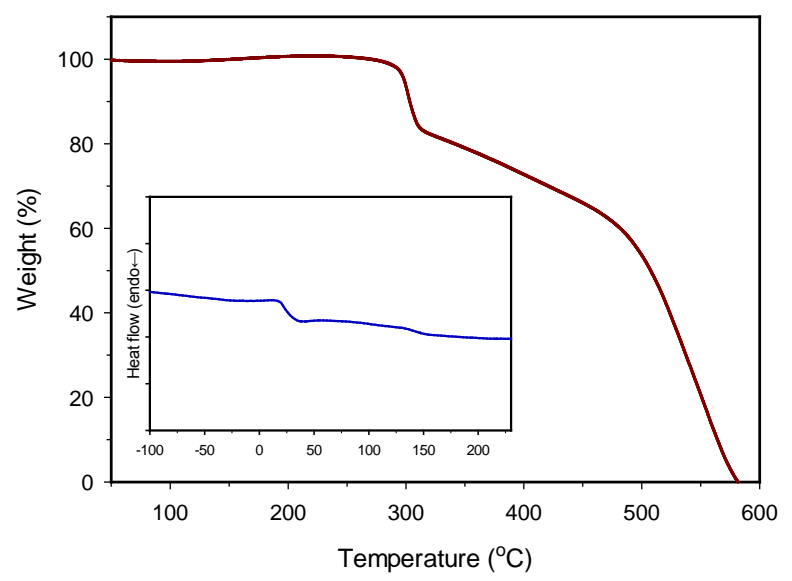

Figure 1. Thermogravimetric and differential scanning calorimetric (inset) traces of PSB at a heating rate of $10^{\circ} \mathrm{C} / \mathrm{min}$ under nitrogen atmosphere.

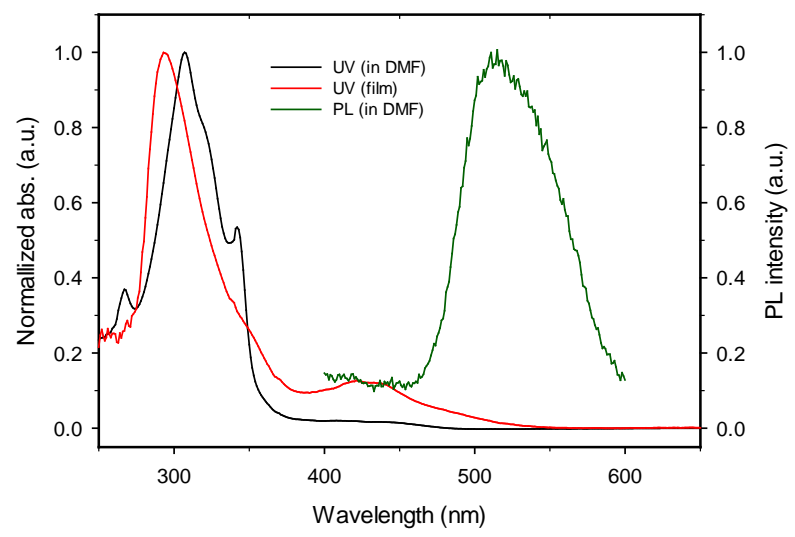

Figure 2. Normalized UV/Vis absorption and photoluminescence spectra of PSB in DMF solution and at film state.

Table 1. Optical properties of PSB.

\begin{tabular}{|c|c|c|c|c|c|}
\hline & \multicolumn{2}{|c|}{$\mathrm{UV} / \mathrm{vis} \lambda_{\max }(\mathrm{nm})$} & \multicolumn{2}{|c|}{ PL $\lambda_{\max }(\mathrm{nm})^{\mathrm{c}}$} & \multirow{2}{*}{$E_{g}^{o m} \quad(e V)^{\mathrm{d}}$} \\
\hline & solution $^{\mathrm{a}}$ & film ${ }^{\mathrm{b}}$ & solution $^{\mathrm{a}}$ & film $^{\mathrm{b}}$ & \\
\hline PSB & $267,307,342$ & 294,430 & 515 & --- & 3.52 \\
\hline
\end{tabular}

${ }^{\mathrm{a}}$ In $10^{-5} \mathrm{M}$ DMF solution. ${ }^{\mathrm{b}}$ The film prepared by spin-coating $10 \mathrm{mg} / \mathrm{mL}$ in DMF solution on quartz substrate. ${ }^{~}$ Excitation wavelength was $307 \mathrm{~nm}$. ${ }^{\mathrm{d}}$ The value was estimated by the $\lambda_{\text {onset }}$ of the UV/Vis spectrum.

Cyclic voltammetric analysis is a powerful method to evaluate electrochemical properties of organic and polymeric materials, especially the estimation of oxidation and reduction potentials. Usually the sample is coated onto the working electrode or dissolved in the electrolyte. The propensity to lose or obtain electron is readily estimated from the oxidation and reduction potentials. The PSB film was deposited onto the glassy carbon electrode by dropping its chloroform solution. The cyclic voltammogram of PSB is shown in Figure 3 and the corresponding electrochemical data are summarized in Table 2. The CV curve was not a closed loop, probably attributed to the equilibrium between PSB and elec- 
trolyte ions was still not established. The highest occupied molecular orbital (HOMO) and lowest unoccupied molecular orbital (LUMO) levels were estimated by

$$
\begin{gathered}
E_{\text {номо }}(e V)=-\left(E_{\text {onset(ox),FOC }}+4.8\right) \\
\text { and } E_{\text {LUMO }}(e V)=-\left(E_{\text {onset(red),FOC }}+4.8\right)
\end{gathered}
$$

where $E_{\text {onset(ox),FOC }}$ and $E_{\text {onset(red),FOC }}$ are the onset oxidation and onset reduction potentials respectively, relative to the ferrocene/ferrocenium couple whose energy level is already known $(-4.8 \mathrm{eV})$. The estimated LUMO and HOMO energy levels are $-2.55 \mathrm{eV}$ and $-6.33 \mathrm{eV}$, respectively. Therefore, the electrochemically determined band-gap $\left(\mathrm{E}_{\mathrm{g}}^{\mathrm{el}}\right)$ is $3.78 \mathrm{eV}$. The estimated LUMO and HOMO levels of PSB are much lower than those of pyrene $(-1.48 \mathrm{eV},-5.44 \mathrm{eV})$ [28], due to the presence of two terminal Schiff base-modified phenol groups. Low HOMO level is effective in reducing hole mobility, which in turn raise carriers' recombination ratio in the emissive layer (Super Yellow) to enhance emission efficiency. Density functional theory (DFT) theory was employed to investigate electron distribution in PSB, using an electronic structure-modeling program Gaussian 09. As shown in Figure 4, the HOMO is exclusively localized on pyrene core, while the LUMO is mainly located on the Schiff base groups and partially on the pyrene core. Therefore, the two Schiff base groups in PSB should be effective in reducing hole mobility due to their electron-withdrawing characteristics.

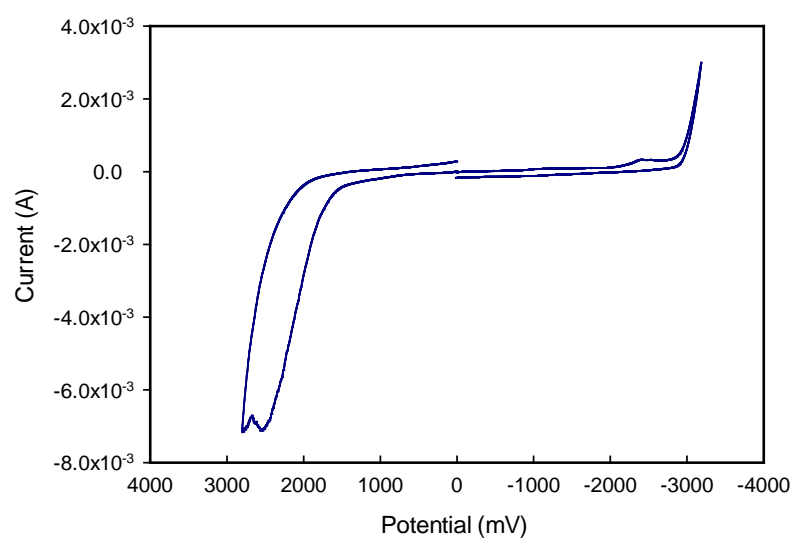

Figure 3. Cyclic voltammogram of PSB coated on carbon electrode, measured in $0.1 \mathrm{M}(\mathrm{n}-\mathrm{Bu}) 4 \mathrm{NClO} 4$; scan rate: 100 $\mathrm{mV} / \mathrm{s}$.

\begin{tabular}{|c|c|c|c|c|c|}
\hline & $\begin{array}{c}E_{\text {onset (ox) vs.FOC }} \\
(\mathrm{V})^{\mathrm{a}}\end{array}$ & $\begin{array}{c}E_{\text {onset (red) vs. FOC }} \\
(\mathrm{V})^{\mathrm{a}}\end{array}$ & $\begin{array}{l}E_{\text {Hомо }} \\
(\mathrm{eV})^{\mathrm{b}}\end{array}$ & $\begin{array}{l}E_{\mathrm{LUMO}} \\
(\mathrm{eV})^{\mathrm{c}}\end{array}$ & $\begin{array}{c}E_{\mathrm{g}}^{\mathrm{el}} \\
(\mathrm{eV})^{\mathrm{d}}\end{array}$ \\
\hline PSB & 1.53 & -2.25 & -6.33 & -2.55 & 3.78 \\
\hline Pyrene [30] & --- & --- & -5.44 & -1.48 & 3.86 \\
\hline
\end{tabular}

Table 2. Electrochemical properties of PSB and pyrene. 


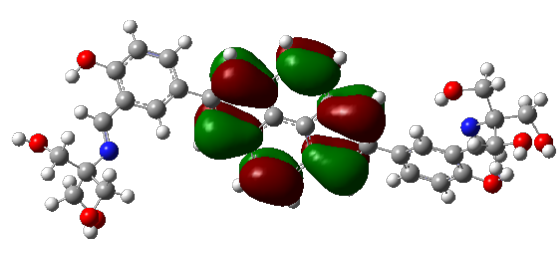

(a)

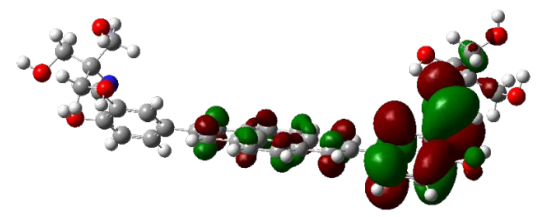

(b)

Figure 4. (a) HOMO and (b) LUMO distributions of PSB calculated by Gaussian 09 software [DFT-B3LYP/6-311G(d) level].

Figure 5 shows the energy level diagrams of hole-buffering and hole-blocking devices. The HOMO level of BCP $(-6.7 \mathrm{eV})$ is much lower than $-5.0 \mathrm{eV}$ of the emissive SY layer. Accordingly, BCP is effective in blocking the holes when inserted between emissive SY layer and the cathode. On the other hand, the HOMO level of PSB $(-6.33 \mathrm{eV})$ is also much lower than $-5.0 \mathrm{eV}$ of the hole-injecting PEDOT:PSS layer. By the same way, PSB can effectively obstruct the holes when inserted between PEDOT:PSS and emissive SY layers. This will reduce transport rate of the holes to raise carrier recombination ratio and emission efficiency, because for most conjugated emissive materials holes transport much faster than electrons [29].

\subsection{Surface Morphology}

Surface morphology of deposited film during device fabrication was observed by an atomic force microscopy (AFM); the root-mean-square (rms) surface roughness was estimated from the AFM topography images. At first, the effect of concentration was investigated using PSB solutions in DMF (5, 10, 15 and 20 $\mathrm{mg} / \mathrm{mL}$ ). The hole-injecting PEDOT:PSS was spin-coated onto ITO substrate at $3000 \mathrm{rpm}$ followed by annealing at $140^{\circ} \mathrm{C}$ for $20 \mathrm{~min}$. The PSB was then spin-coated on top of the PEDOT:PSS layer first at $2000 \mathrm{rpm}$ for $15 \mathrm{sec}$ and then at $6000 \mathrm{rpm}$ for $1 \mathrm{~min}$. The spin-coated PSB film was annealed at $70^{\circ} \mathrm{C}$ for 20 min under nitrogen atmosphere. Figure 6 shows the AFM topography images. The root-mean-square (rms) surface roughness of the PEDOT:PSS layer was $1.18 \mathrm{~nm}$ which is comparable to that reported in literature. PSB films revealed smooth morphology when spin-coated from lower concentrations (5 and 10 $\mathrm{mg} / \mathrm{mL}$ ), with surface roughness of $1.88 \mathrm{~nm}$ and $2.08 \mathrm{~nm}$, respectively. However, the surface became much rougher when spin-coated from higher concentrations (15 and $20 \mathrm{mg} / \mathrm{mL}$ ), with the roughness of $10.70 \mathrm{~nm}$ and $9.77 \mathrm{~nm}$, respectively.

\subsection{Electroluminescent Properties}

To investigate the feasibility of PBS as a hole-buffering material, multilayer PLED devices were fabricated [ITO/PEDOT:PSS $(40 \mathrm{~nm}) / \mathrm{PSB}(\mathrm{x} \mathrm{nm}) / \mathrm{SY}$ (70 $\mathrm{nm}) / \mathrm{LiF}(1 \mathrm{~nm}) / \mathrm{Al}(90 \mathrm{~nm})]$ and their optoelectronic characteristics measured. For comparative study, multilayer blank PLED device without the PSB layer [ITO/PEDOT:PSS $(40 \mathrm{~nm}) / \mathrm{SY}(70 \mathrm{~nm}) / \operatorname{LiF}(1 \mathrm{~nm}) / \mathrm{Al}(90 \mathrm{~nm})]$ was also fabricated. Moreover, the device with conventional $\mathrm{BCP}$ as a hole-blocking layer 


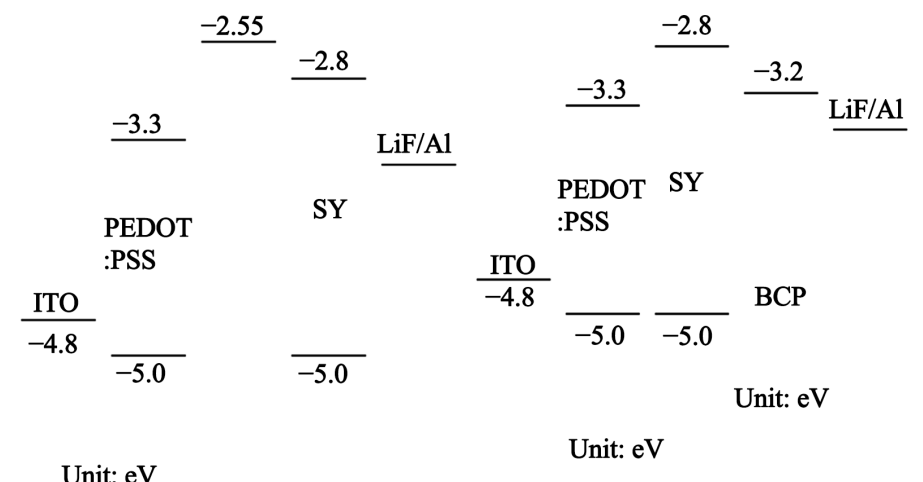

$\overline{-6.33}$

(a)

\section{$\overline{-6.7}$}

(b)

Figure 5. Energy level diagrams of the PLEDs using (a) PSB as hole-buffering layer and (b) BCP as hole-blocking layer.

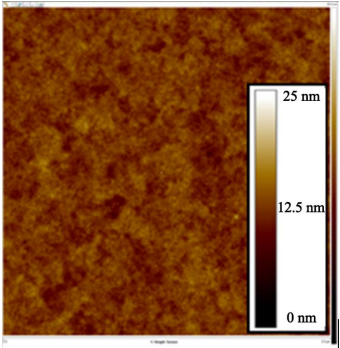

(a)

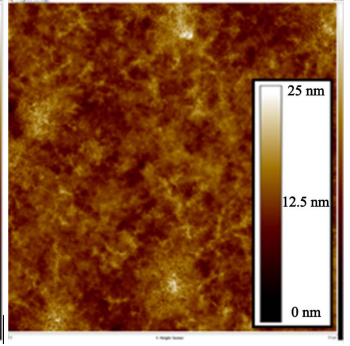

(b)

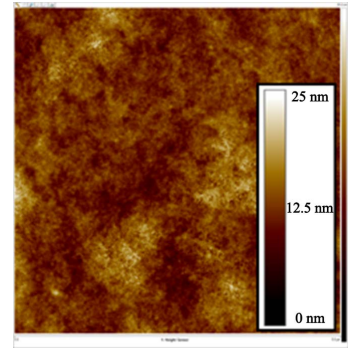

(c)

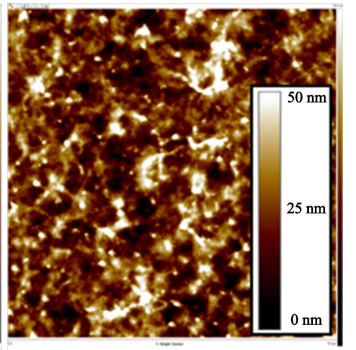

(d)

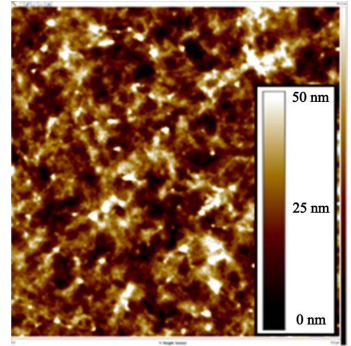

(e)

Figure 6. AFM images of (a) PEDOT:PSS film on top of ITO and PSB on top of the PEDOT:PSS film coated from different concentration; (b) $5 \mathrm{mg} / \mathrm{mL}$; (c) 10 $\mathrm{mg} / \mathrm{mL}$; (d) $15 \mathrm{mg} / \mathrm{mL}$; (e) $20 \mathrm{mg} / \mathrm{mL}$.

[ITO/PEDOT:PSS (40 nm)/SY (70 nm)/BCP (15 nm)/LiF (1 nm)/Al (90 nm)] was also prepared to evaluate the effectiveness of hole-buffering PSB. Figure 7 demonstrates luminance and current density versus voltage and efficiency versus current density of the multilayer devices, with the characteristic data summarized in Table 3. The hole-buffer layer was inserted between hole-injecting PEDOT:PSS and emissive SY layers by spin-coating PSB solutions with different concentrations $(5,7,10,15,20 \mathrm{mg} / \mathrm{mL})$. The thickness of deposited PSB films was increased gradually from $7 \mathrm{~nm}$ to $38 \mathrm{~nm}$ with the concentration increasing from $5 \mathrm{mg} / \mathrm{mL}$ to $20 \mathrm{mg} / \mathrm{mL}$ (Table 3).

As expected, insertion of hole-blocking BCP layer $(15 \mathrm{~nm})$ decreases current 
density moderately under the same operating voltages (Figure 7(b)); for instance, the current density of blank device was about $200 \mathrm{~mA} / \mathrm{cm}^{2}$ at $8 \mathrm{~V}$ which decreased to ca. $100 \mathrm{~mA} / \mathrm{cm}^{2}$ after the insertion of BCP. The BCP layer effectively blocks the holes at the interface with the emissive SY layer. However, hole-buffering PSB layer reduced the current density dramatically, with the reduction increased with thickness. In addition, the maximum luminance of PSB-based device increased significantly from $9060 \mathrm{~cd} / \mathrm{m}^{2}$ to $26,439 \mathrm{~cd} / \mathrm{m}^{2}$ as the thickness increased from $7 \mathrm{~nm}$ to $15 \mathrm{~nm}$ (Table 3). Apparently, the maximum luminance $\left(26,439 \mathrm{~cd} / \mathrm{m}^{2}\right)$ at $15 \mathrm{~nm}$ PSB is much higher than $9802 \mathrm{~cd} / \mathrm{m}^{2}$ and $15,496 \mathrm{~cd} / \mathrm{m}^{2}$ of the blank and BCP-based devices, respectively. However, the maximum luminance dropped dramatically to $8103 \mathrm{~cd} / \mathrm{m}^{2}$ and $5812 \mathrm{~cd} / \mathrm{m}^{2}$ when the thickness of PSB further increased to $24 \mathrm{~nm}$ and $38 \mathrm{~nm}$ respectively. Clearly, an optimal PSB thickness exists at about $15 \mathrm{~nm}$, at which the balance of carriers is most effective.

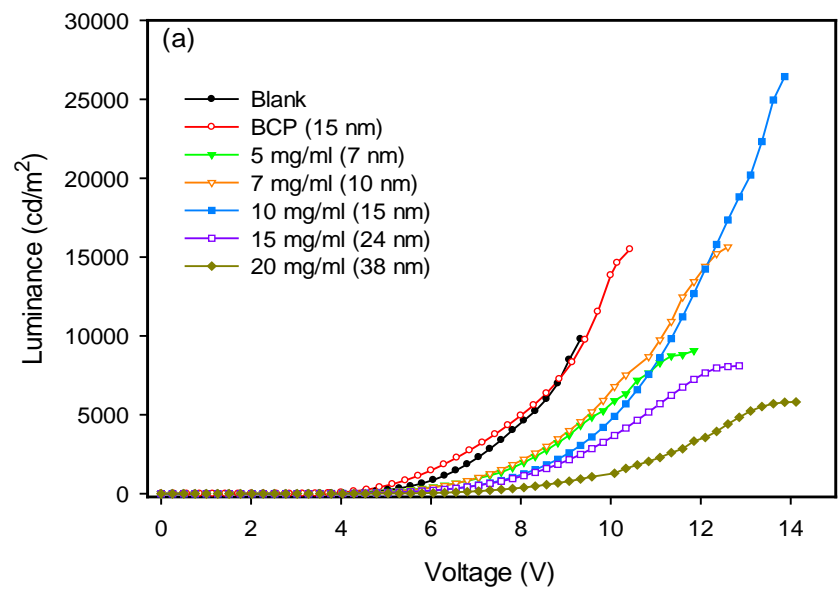

(a)

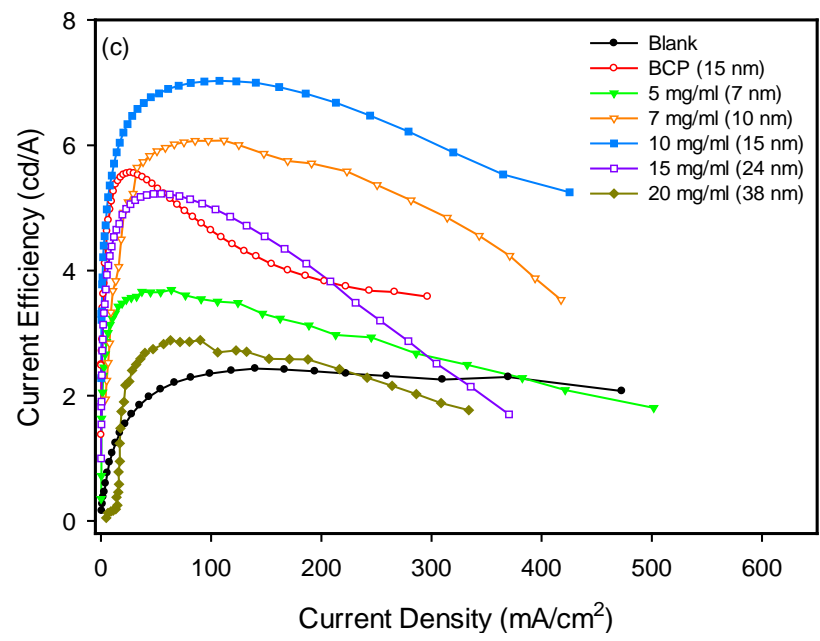

(c)

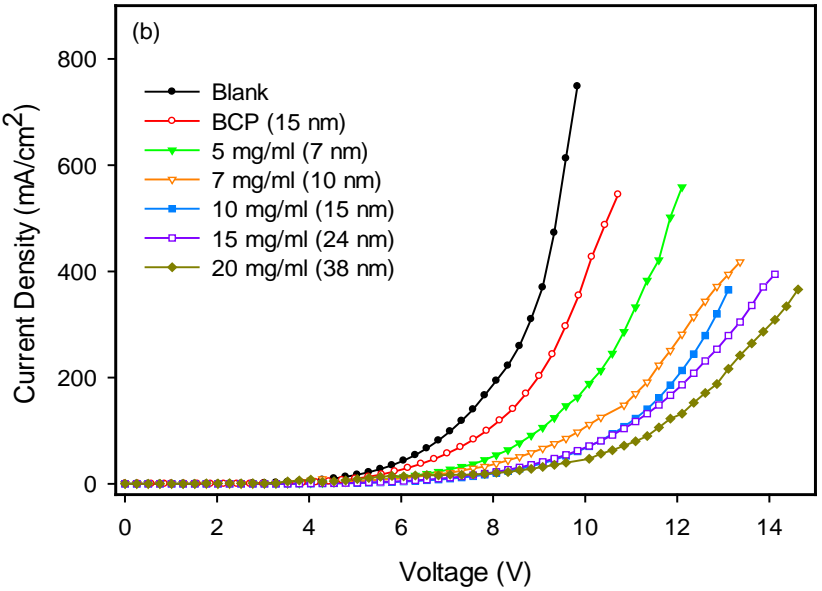

(b)

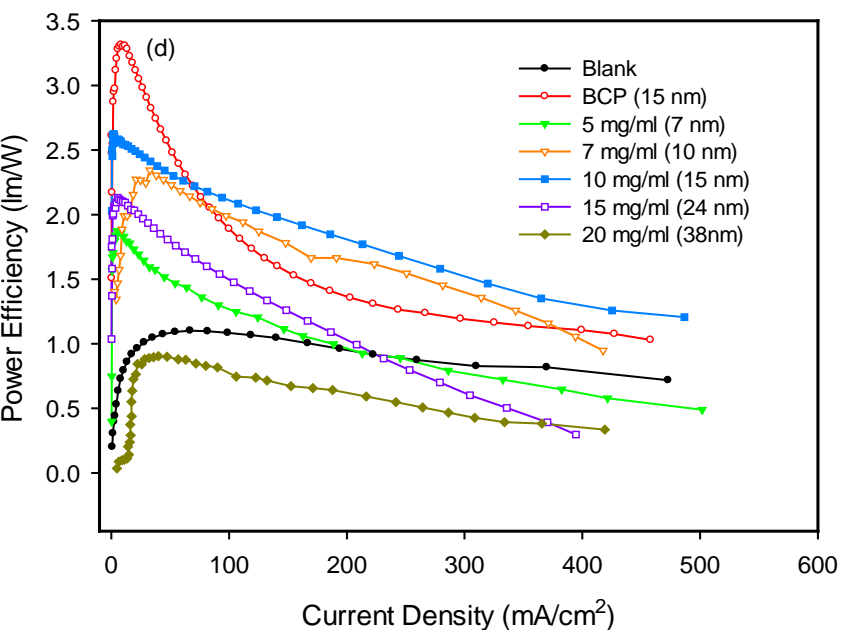

(d)

Figure 7. (a) Luminance versus voltage; (b) current density versus voltage; (c) current efficiency versus current density and (d) power efficiency versus current density characteristics of the OLEDs using PSB as hole-buffer layer. Device structure: ITO/PEDOT:PSS/PSB(x nm)/SY/(BCP)/LiF/Al. 
Table 3. Electroluminescent properties of multilayer PLEDs. ${ }^{a}$

\begin{tabular}{ccccccc}
\hline & Thickness $^{\mathrm{b}}$ & $\mathrm{V}_{\text {on }}{ }^{\mathrm{c}}$ & $\mathrm{L}_{\max }{ }^{\mathrm{d}}$ & $\mathrm{CE}_{\max }{ }^{\mathrm{e}}$ & $\mathrm{PE}_{\max }{ }^{\mathrm{f}}$ & $\mathrm{CIE}^{\mathrm{g}}$ \\
\cline { 2 - 6 } & $(\mathrm{nm})$ & $(\mathrm{V})$ & $\left(\mathrm{cd} / \mathrm{m}^{2}\right)$ & $(\mathrm{cd} / \mathrm{A})$ & $(\mathrm{lm} / \mathrm{W})$ & $(\mathrm{x}, \mathrm{y})$ \\
\hline Blank & --- & 3.3 & 9802 & 2.43 & 1.10 & $(0.40,0.58)$ \\
BCP & 15 & 3.3 & 15,496 & 5.56 & 3.31 & $(0.42,0.57)$ \\
$5 \mathrm{mg} / \mathrm{mL}^{\mathrm{h}}$ & 7 & 3.5 & 9060 & 3.69 & 1.87 & $(0.44,0.55)$ \\
$7 \mathrm{mg} / \mathrm{mL}^{\mathrm{h}}$ & 10 & 3.7 & 15,640 & 6.08 & 2.30 & $(0.45,0.54)$ \\
$10 \mathrm{mg} / \mathrm{mL}^{\mathrm{h}}$ & 15 & 3.9 & 26,439 & 7.03 & 2.62 & $(0.46,0.52)$ \\
$15 \mathrm{mg} / \mathrm{mL}^{\mathrm{h}}$ & 24 & 4.0 & 8103 & 5.26 & 2.13 & $(0.46,0.53)$ \\
$20 \mathrm{mg} / \mathrm{mL}^{\mathrm{h}}$ & 38 & 4.9 & 5812 & 2.89 & 0.90 & $(0.46,0.53)$ \\
\hline
\end{tabular}

${ }^{\text {a}}$ Device structure: ITO/PEDOT:PSS $(40 \mathrm{~nm}) / \mathrm{PSB}(\mathrm{x} \mathrm{nm}) / \mathrm{SY}(70 \mathrm{~nm}) /[\mathrm{BCP}(15 \mathrm{~nm})] / \mathrm{LiF}(1 \mathrm{~nm}) / \mathrm{Al}(90$ $\mathrm{nm})$. ${ }^{\mathrm{b}}$ Thickness was determined by alpha-step measurement. ${ }^{\circ}$ Turn-on voltage at $10 \mathrm{~cd} / \mathrm{m}^{2} .{ }^{\mathrm{d}}$ Maximum luminance. ${ }^{\mathrm{e}}$ Maximum current efficiency. ${ }^{\mathrm{f}} \mathrm{Maximum}$ power efficiency. ${ }^{\mathrm{g}} \mathrm{The} 1931 \mathrm{CIE}$ coordinate at maximum current efficiency. ${ }^{\mathrm{h} C o n c e n t r a t i o n}$ of PSB in DMF.

Similar trends are observed for current efficiency and power efficiency as shown in Figure 7 (c) and Figure 7(d) and Table 3. The maximum current efficiency first increased from $3.69 \mathrm{~cd} / \mathrm{A}$ to $7.03 \mathrm{~cd} / \mathrm{A}$, followed with dramatic drop to 5.26 and $2.89 \mathrm{~cd} / \mathrm{A}$ at $24 \mathrm{~nm}$ and $38 \mathrm{~nm}$, respectively. However, these current efficiencies are still higher than $2.43 \mathrm{~cd} / \mathrm{A}$ of the blank device. Furthermore, hole-buffering PSB is more effective than hole-blocking BCP in enhancingefficiency. Under the same thickness $(15 \mathrm{~nm})$, the current efficiency of PSB-based device was $7.03 \mathrm{~cd} / \mathrm{A}$, compared with $5.56 \mathrm{~cd} / \mathrm{A}$ of BCP-based one. But the PSB layer raised turn-on voltage gradually from $3.3 \mathrm{~V}$ to $4.9 \mathrm{~V}$ when its thickness was increased from $7 \mathrm{~nm}$ to $38 \mathrm{~nm}$. Apparently, inserting hole-buffering PSB results in significant performance enhancement, in terms of maximum luminance and current efficiency, compared with blank device (Table 3). The performance is even superior to the device with conventional $\mathrm{BCP}$ as the hole-blocking layer (maximum luminance: $15,496 \mathrm{~cd} / \mathrm{m}^{2}$, maximum current efficiency: $5.56 \mathrm{~cd} / \mathrm{A}$ ). These results indicate that hole-buffering PSB outperforms hole-blocking BCP when applied to balance carriers' recombination. Single-carrier transporting devices are thought effective in elucidating underlying mechanisms, whose discussion is in the next section.

Single-carrier devices (hole-only and electron-only) with hole-buffering (PSB) or hole-blocking (BCP) layers were fabricated to investigate charge-transporting properties. The hole-only device used $\mathrm{Au}$ as cathode to replace $\mathrm{LiF} / \mathrm{Al}$, whereas the electron-only one employed $\mathrm{ZnO}$ to replace hole-injecting PEDOT:PSS. For hole-only device, large barrier height between Au (work function: $5.1 \mathrm{eV}$ ) and emissive SY layer (LUMO: $-2.8 \mathrm{eV}$ ) obstructs electron injection, resulting in exclusive holes' contribution to current density. Similarly, for electron-only device, the barrier height between $\mathrm{ZnO}(-7.6 \mathrm{eV})$ and ITO anode $(-4.8 \mathrm{eV})$ is very high $(2.8 \mathrm{eV})$, leading to exclusive contribution of electrons. Therefore, the current density of hole-only and electron-only devices can be seen as hole density and electron density. For hole-only devices (Figure 8(a)), current density reduced 
dramatically with $7 \mathrm{~nm}$ PSB or $15 \mathrm{~nm} \mathrm{BCP}$ as hole-bufferingor hole-blocking layer. Moreover, the reduction increased gradually with increasing thickness of PSB (from $7 \mathrm{~nm}$ to $38 \mathrm{~nm}$ ).

On the contrary, for electron-only devices the current density increased only slightly with PSB thickness (from $7 \mathrm{~nm}$ to $15 \mathrm{~nm}$ ) as shown in Figure 8(b). Further increase to $24 \mathrm{~nm}$ and $38 \mathrm{~nm}$ the current density became lower than the blank device. However, the BCP layer $(15 \mathrm{~nm})$ raised the current density significantly. This is because BCP, inserted between emissive SY and Al cathode, is also an effective electron injection/transport material due to its low LUMO level $(-3.2 \mathrm{eV})$, in addition to its hole-blocking capability (low HOMO level). The PSB layer, inserted between emissive SY and $\mathrm{ZnO}$, promotes electron transport slightly at low thickness $(7-15 \mathrm{~nm})$ due probably to polar and electron-withdrawing imine and trihydroxy tert-butyl groups. Interfacial polarization in carrier-transporting layer contributes greatly to the promotion of carriers' injection. However, the contribution gradually diminishes with increasing thickness due to decreased polarity gradient.

The results indicate both PSB and BCP reduce transport rate of the holes to enhance carrier balance and device performance. Moreover, The PSB is inserted between hole-injecting PEDOT:PSS and emitting SY layers to reduce hole's transport into SY layer. This leads to more homogeneous distribution of the excitons formed in the SY layer. However, the BCP layer is inserted between the emitting SY layer and the LiF/Al cathode to block the holes from quenching at the cathode. This blocking accumulates a large amount of the holes in a narrow region near the interface between the emitting SY and BCP layers. Therefore, the distribution of the excitons in emitting SY layer is very different for PSB and BCP devices. As shown in Figure 9(a), the recombination region for BCP-based device is narrow and close to the interface of the emitting SY and BCP layers. On the contrary, recombination region for PSB device should be much more

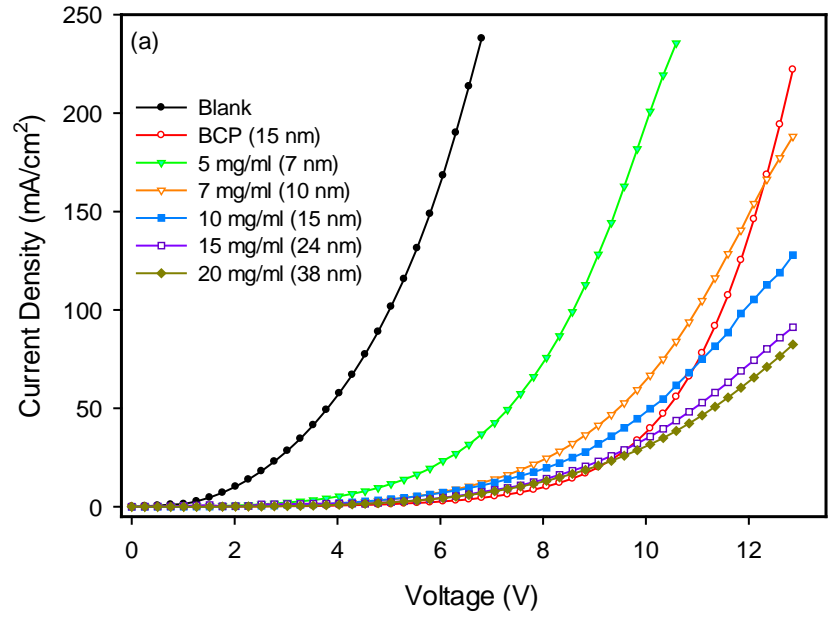

(a)

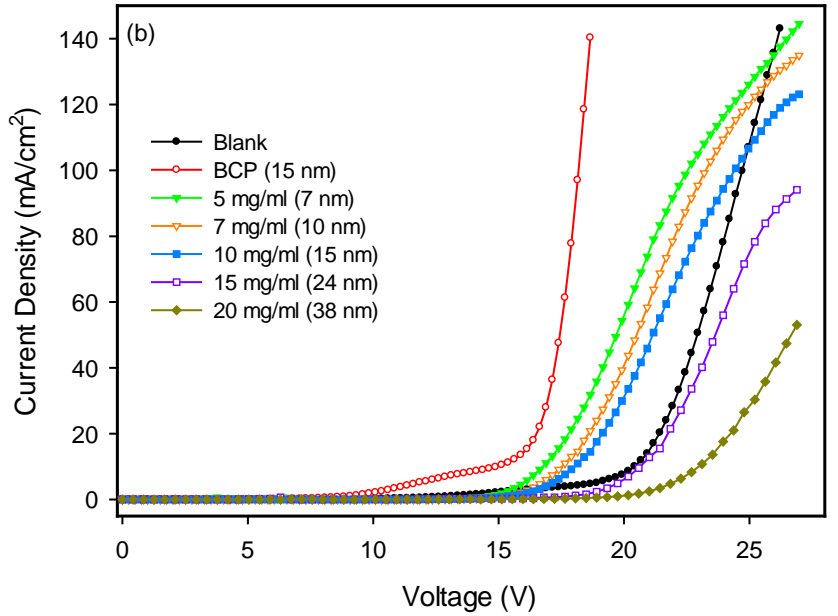

(b)

Figure 8. Current density versus voltage characteristics of (a) hole-only and (b) electron-only EL devices. Devices structure: (a) HOD: ITO/PEDOT:PSS/PSB (x nm)/SY/(BCP)/Au; (b) EOD: ITO/ZnO/PSB (x nm)/SY/(BCP)/LiF/Al. 


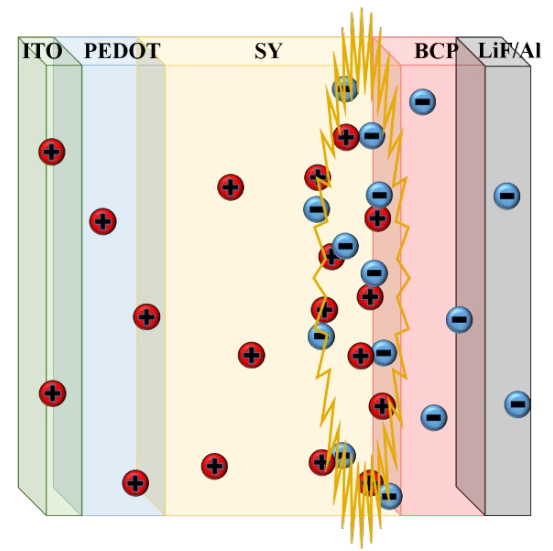

(a)

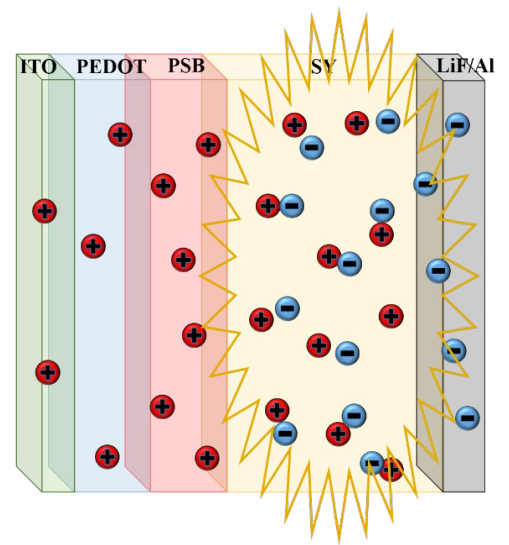

(b)

Figure 9. Proposed illustrations for recombination region of holes and electrons in the PLEDs using (a) hole-blocking layer (BCP) and (b) hole-buffer layer (PSB).

homogeneous and broader (Figure 9(b)). Broader charges recombination region usually results higher charges' recombination ratio and device performance [30] [31] [32].

\section{Conclusion}

We have successfully synthesized a new compound PSB composed of pyrene core linked with trihydroxy tert-butyl groups through imine moiety by the Suzuki-coupling reaction and applied as hole-buffer layer in multilayer PLEDs. Thermal decomposition temperature $\left(\mathrm{T}_{\mathrm{d}}\right)$ at $5 \%$ weight loss was observed at $300^{\circ} \mathrm{C}$. The HOMO and LUMO levels of PSB were -6.33 and $-2.55 \mathrm{eV}$ respectively, estimated from onset oxidation and reduction potentials determined by cyclic voltammetry. Multilayer PLEDs have been successfully fabricated (ITO/PEDOT:PSS/PSB/SY/LiF/Al), in which PEDOT:PSS, PSB and SY layers were deposited by spin-coating process. The thickness of PSB layer increased gradually from $7 \mathrm{~nm}$ to $38 \mathrm{~nm}$ with PSB concentration increased from 5 $\mathrm{mg} / \mathrm{mL}$ to $20 \mathrm{mg} / \mathrm{mL}$ in DMF. Inserting PSB as hole-buffer layer effectively raised luminance and emission efficiency, with optimal PSB thickness being 15 $\mathrm{nm}$. The maximum luminance and maximum current efficiency were 26,439 $\mathrm{cd} / \mathrm{m}^{2}$ and $7.03 \mathrm{~cd} / \mathrm{A}$, respectively, which were superior to $9802 \mathrm{~cd} / \mathrm{m}^{2}$ and 2.43 $\mathrm{cd} / \mathrm{A}$ of the blank device. Under the same thickness $(15 \mathrm{~nm})$, the PSB-based device also outperformed the one with the conventional $\mathrm{BCP}$ as hole-blocking layer [ITO/PEDOT:PSS/SY/BCP/LiF/Al],in terms of maximum luminance and maximum current efficiency $\left(15,496 \mathrm{~cd} / \mathrm{m}^{2}, 5.56 \mathrm{~cd} / \mathrm{A}\right)$. Current results indicate that the PSB composed of pyrene, polar imine and trihydroxy tert-butyl groups is highly effective in buffering holes' transport to enhance performance of electroluminescent devices.

\section{Acknowledgements}

Authors are thankful to the Ministry of Science and Technology (MOST) of 
Taiwan for financial support through grant MOST105-2221-E-006-250.

\section{References}

[1] Burroughes, J., Bradley, D., Brown, A., Marks, R., Mackay, K., Friend, R., Burns, P. and Holmes, A. (1990) Light-Emitting Diodes Based on Conjugated Polymers. Nature, 347, 539-541. https://doi.org/10.1038/347539a0

[2] Burrows, P.E., Graff, G.L., Gross, M.E., Martin, P.M., Shi, M.-K., Hall, M., Mast, E., Bonham, C., Bennett, W. and Sullivan, M.B. (2001) Ultra Barrier Flexible Substrates for Flat Panel Displays. Displays, 22, 65-69. https://doi.org/10.1016/S0141-9382(00)00064-0

[3] Sugimoto, A., Ochi, H., Fujimura, S., Yoshida, A., Miyadera, T. and Tsuchida, M. (2004) Flexible OLED Displays Using Plastic Substrates. IEEE Journal of Selected Topics in Quantum Electronics, 10, 107-114. https://doi.org/10.1109/JSTQE.2004.824112

[4] Qiu, Y., Gao, Y., Wei, P. and Wang, L. (2002) Organic Light-Emitting Diodes with Improved Hole-Electron Balance by Using Copper Phthalocyanine/Aromatic Diamine Multiple Quantum Wells. Applied Physics Letters, 80, 2628-2630. https://doi.org/10.1063/1.1468894

[5] Yin, S., Yi, Y., Li, Q., Yu, G., Liu, Y. and Shuai, Z. (2006) Balanced Carrier Transports of Electrons and Holes in Silole-Based Compounds-A Theoretical Study. Journal of Physical Chemistry A, 110, 7138-7143. https://doi.org/10.1021/jp057291o

[6] Yamashita, Y. (2009) Organic Semiconductors for Organic Field-Effect Transistors. Science and Technology of Advanced Materials, 10, Article ID: 024313.

https://doi.org/10.1088/1468-6996/10/2/024313

[7] Hung, L., Tang, C.W. and Mason, M.G. (1997) Enhanced Electron Injection in Organic Electroluminescence Devices Using an $\mathrm{Al} / \mathrm{LiF}$ Electrode. Applied Physics Letters, 70, 152-154. https://doi.org/10.1063/1.118344

[8] Brown, T., Kim, J., Friend, R., Cacialli, F., Daik, R. and Feast, W. (1999) Built-In Field Electroabsorption Spectroscopy of Polymer Light-Emitting Diodes Incorporating a Doped Poly (3, 4-Ethylene Dioxythiophene) Hole Injection Layer. Applied Physics Letters, 75, 1679-1681. https://doi.org/10.1063/1.124789

[9] Adamovich, V.I., Cordero, S.R., Djurovich, P.I., Tamayo, A., Thompson, M.E., D'Andrade, B.W. and Forrest, S.R. (2003) New Charge-Carrier Blocking Materials for High Efficiency OLEDs. Organic Electronics, 4, 77-87.

https://doi.org/10.1016/j.orgel.2003.08.003

[10] Lin, W.C., Lin, H.W., Mondal, E. and Wong, K.T. (2015) Efficient Solution-Processed Green and White Phosphorescence Organic Light-Emitting Diodes Based on Bipolar Host Materials. Organic Electronics, 17, 1-8. https://doi.org/10.1016/j.orgel.2014.11.002

[11] Gao, H., Qin, C., Zhang, H., Wu, S., Su, Z.M. and Wang, Y. (2008) Theoretical Characterization of a Typical Hole/Exciton-Blocking Material Bathocuproine and Its Analogues. Journal of Physical Chemistry A, 112, 9097-9103. https://doi.org/10.1021/jp804308e

[12] Ikai, M., Tokito, S., Sakamoto, Y., Suzuki, T. and Taga, Y. (2001) Highly Efficient Phosphorescence from Organic Light-Emitting Devices with an Exciton-Block Layer. Applied Physics Letters, 79, 156-158. https://doi.org/10.1063/1.1385182

[13] Su, H.-C. and Hsu, J.-H. (2015) Improving the Carrier Balance of Light-Emitting Electrochemical Cells Based on Ionic Transition Metal Complexes. Dalton Transac- 
tions, 44, 8330-8345. https://doi.org/10.1039/C4DT01675K

[14] Xia, Y.-J., Lin, J., Tang, C., Yin, K., Zhong, G.-Y., Ni, G., Peng, B., Gan, F.-X. and Huang, W. (2006) High-Efficiency Blue-Emitting Organic Light-Emitting Devices with 4, 4', 4"-Tris (N-Carbazolyl)-Triphenylamine as the Hole/Exciton-Blocking Layer. Journal of Physics D: Applied Physics, 39, 4987. https://doi.org/10.1088/0022-3727/39/23/013

[15] Tadayyon, S.M., Grandin, H.M., Griffiths, K., Norton, P.R., Aziz, H. and Popovic, Z.D. (2004) CuPc Buffer Layer Role in OLED Performance: A Study of the Interfacial Band Energies. Organic Electronics, 5, 157-166. https://doi.org/10.1016/j.orgel.2003.10.001

[16] Chou, S.-Y. and Chen, Y. (2016) Hole-Buffer Polymer Composed of Alternating p-Terphenyl and Tetraethylene Glycol Ether Moieties: Synthesis and Application in Polymer Light-Emitting Diodes. Journal of Polymer Science Part A: Polymer Chemistry, 54, 785-794. https://doi.org/10.1002/pola.27911

[17] Lee, S.J., Lee, S.E., Lee, D.H., Koo, J.R., Lee, H.W., Yoon, S.S., Park, J. and Kim, Y.K. (2014) Effect of Broad Recombination Zone in Multiple Quantum Well Structures on Lifetime and Efficiency of Blue Organic Light-Emitting Diodes. Japanese Journal of Applied Physics, 53, Article ID: 101601. https://doi.org/10.7567/JJAP.53.101601

[18] Forsythe, E., Abkowitz, M. and Gao, Y. (2000) Tuning the Carrier Injection Efficiency for Organic Light-Emitting Diodes. Journal of Physical Chemistry B, 104, 3948-3952. https://doi.org/10.1021/jp9937930

[19] Shibata, M., Sakai, Y. and Yokoyama, D. (2015) Advantages and Disadvantages of Vacuum-Deposited and Spin-Coated Amorphous Organic Semiconductor Films for Organic Light-Emitting Diodes. Journal of Materials Chemistry C, 3, 11178-11191. https://doi.org/10.1039/C5TC01911G

[20] Duan, L., Hou, L., Lee, T.-W., Qiao, J., Zhang, D., Dong, G., Wang, L. and Qiu, Y. (2010) Solution Processable Small Molecules for Organic Light-Emitting Diodes. Journal of Materials Chemistry, 20, 6392-6407. https://doi.org/10.1039/b926348a

[21] Otsubo, T., Aso, Y. and Takimiya, K. (2002) Functional Oligothiophenes as Advanced Molecular Electronic Materials. Journal of Materials Chemistry, 12, 2565-2575. https://doi.org/10.1039/b203780g

[22] Ferguson, J. (1958) Absorption and Fluorescence Spectra of Crystalline Pyrene. Journal of Chemical Physics, 28, 765-768. https://doi.org/10.1063/1.1744267

[23] Hsu, P.-F. and Chen, Y. (2018) Synthesis of a Pyrene-Derived Schiff Base and Its Selective Fluorescent Enhancement by Zinc and Aluminum Ions. International Journal of Organic Chemistry.

[24] Qiao, Y.L., Zhang, J., Xu, W. and Zhu, D.B. (2011) Novel 2,7-Substituted Pyrene Derivatives: Syntheses, Solid-State Structures, and Properties. Tetrahedron, 67, 3395-3405. https://doi.org/10.1016/j.tet.2011.03.055

[25] Rathfon, J.M., AL-Badri, Z.M., Shunmugam, R., Berry, S.M., Pabba, S., Keynton, R.S., Cohn, R.W. and Tew, G.N. (2009) Fluorimetric Nerve Gas Sensing Based on Pyrene Imines Incorporated into Films and Sub-Micrometer Fibers. Advanced Functional Materials, 19, 689-695. https://doi.org/10.1002/adfm.200800947

[26] Ou, C.J., Lei, Z.F., Sun, M.L., Xie, L.H., Qian, Y., Zhang, X.W. and Huang, W. (2015) Dumbbell Effects of Solution-Processed Pyrene-Based Organic Semiconductors on Electronic Structure, Morphology and Electroluminescence. Synthetic Metals, 200, 135-142. https://doi.org/10.1016/j.synthmet.2014.12.034

[27] Hsieh, W.H., Wan, C.F., Liao, D.J. and Wu, A.T. (2012) A Turn-On Schiff Base Flu-Orescence Sensor for Zinc Ion. Tetrahedron Letters, 53, 5848-5851. 
https://doi.org/10.1016/j.tetlet.2012.08.058

[28] Chercka, D., Yoo, S.J., Baumgarten, M., Kim, J.J. and Mullen, K. (2014) Pyrene Based Materials for Exceptionally Deep Blue OLEDs. Journal of Materials Chemistry C, 2, 9083-9086. https://doi.org/10.1039/C4TC01801J

[29] Wang, B.C., Chang, J.C., Tso, H.C., Hsu, H.F. and Cheng, C.Y. (2003) Theoretical Investigation the Electroluminescence Characteristics of Pyrene and Its Derivatives. Journal of Molecular Structure: THEOCHEM, 629, 11-20. https://doi.org/10.1016/S0166-1280(02)00787-X

[30] Malliaras, G.G. and Scott, J.C. (1998) The Roles of Injection and Mobility in Organic Light Emitting Diodes. Journal of Applied Physics, 83, 5399-5403. https://doi.org/10.1063/1.367369

[31] Liao, C.T., Chen, H.F., Su, H.C. and Wong, K.T. (2011) Tailoring Balance of Carrier Mobilities in Solid-State Light-Emitting Electrochemical Cells by Doping a Carrier Trapper to Enhance Device Efficiencies. Journal of Materials Chemistry, 21, 17855-17862. https://doi.org/10.1039/c1jm13245h

[32] Lee, S.E., Lee, H.W., Lee, J.W., Hwang, K.M., Park, S.N., Yoon, S.S. and Kim, Y.K. (2015) Optimization of Hybrid Blue Organic Light-Emitting Diodes Based on Singlet and Triplet Exciton Diffusion Length. Japanese Journal of Applied Physics, 54, Article ID: 06FG09. https://doi.org/10.7567/JJAP.54.06FG09 